\title{
Evaluation of electricity consumption and carbon footprint of UI GreenMetric participating universities using regression analysis
}

\author{
Alfan Presekal ${ }^{1, *}$, Herdis Herdiansyah ${ }^{2}$, Ruki Harwahyu ${ }^{1}$, Nyoman Suwartha ${ }^{3}$, and Riri Fitri Sari ${ }^{1}$ \\ ${ }^{1}$ Department of Electrical Engineering, Faculty of Engineering, Universitas Indonesia, Kampus UI Depok, Depok 16424, Indonesia \\ ${ }^{2}$ School of Environmental Science, Universitas Indonesia, Kampus UI Salemba, Jakarta 10430, Indonesia \\ ${ }^{3}$ Department of Civil Engineering, Faculty of Engineering, Universitas Indonesia, Kampus UI Depok, Depok 16424, Indonesia
}

\begin{abstract}
UI GreenMetric as sustainability-based university rankings has received a worldwide acceptance since its initiation in 2010. One of the criteria for this ranking is the annual electricity consumption of participating Universities. There are some challenges in evaluating the overall data, i.e. some electricity consumption information is missing or may not accurately represent the real condition. There is various information that can be used to calculate the university rank associated with electricity consumption. On the other hand, some external data sources from World Bank on the annual electricity consumption per capita for every country is highly correlated with the electricity consumption in every University. This paper aims to show our evaluation and prediction of the annual electricity consumption from participating university using regression analysis based on the available data of UI GreenMetric and relevant external information. This is conducted using regression analysis on the data submitted in 2017 and the predicted KWH based on the number of full-time student and staff in the university. The result shows that some universities are consuming more electricity than the average KWH used per-capita in their country. The result also shows that the prediction cannot be used accurately, especially for the carbon footprint. This evaluation may help universities to improve their policy in reducing the electricity consumption and the greenhouse gas emission reduction policy, and mainly helps UI GreenMetric to speed up the verification process when necessary
\end{abstract}

\section{Background}

UI GreenMetric has already been running for almost 10 years. The number of participating Universities already reach more than 600 in 2017. There are various parameters used by UI GreenMetric for scoring. One of the parameters is university's annual electricity usage. In this ranking, this parameter belongs to the Energy and Climate Change category. Basically, university with more efficient electricity consumption will get better score which at the end determines the rank. Unfortunately, data about electricity consumption sometimes are incomplete or inaccurate. In UI GreeMetric's system, there are two causes that made the data incomplete of inaccurate. The first cause is that the university might have left the field blank or filled it with zero valye. The second reason is that the data can be illogically large or small, i.e. outliers. With everincreasing UI GreenMetric's member and received data, this incomplete and inaccurate data may decrease the accuracy and validity of the generated ranks.

Related with electricity, UI Greenmetrics also perform analysis into carbon footprint. Participating Universities required to calculate their own carbon footprint. Electricity is one key aspect to determine quantity of carbon footprint. Data the carbon footprint also has same problem with electricity. This work aims to find relation between electricity consumption and carbon footprint output.

This paper consists of 5 parts. The first part is background of this work which related with UI Greenmetric University Ranking. Second part of this paper explain about ecological footprint perspective for electricity consumption and carbon footprint. Third part elaborate methodology of collecting data and data analysis from this work. This is followed by fourth part which contains result and discussion, and the last part consist of concluding remarks from this works.

\section{Ecological footprints}

There are various measurements instrument and the concept of 'green' which in uses. Ecological Footprint (EF) was introduced in 1990 by Mathis Wackernagel and William Rees in the book "Our Ecological Footprint" [7]. Ecological Footprint was to convey the method for calculating EF and Ecological Footprint Analysis (EFA). In this book, based on the former activity by humans on earth, namely measuring trace of human level of interaction with nature. Wackernagel and Yount explained that the analysis of the EF is the assessment 
tool to calculate the level of human interaction and disposal [3]. Data collection and calculated of greenhouse gases (GHG) emitted from the atmosphere during a certain time period (the US Environmental Protection Agency, 2009), studied by Mieko A. Ozeki to serve as the basis of mitigation and adaptation to climate [6]. The difference between GHG inventory EF and EF is that it does not fully take into account climate change due to greenhouse gases. Climate mitigation and adaptation planning are also studied by Jeongho Kyoung-Sik Woo and Choi [8], they introduced concept called energy saving action program. The study determines the standard model in the university laboratory for implementation energy saving action program to implement the study guide. The result of research shows that energy saving action program to saving of power consumption significantly.

Carbon Footprint to illustrate the total carbon emissions from all everyday activities. An example is the use of fossil fuels [4]. There are two types of carbon footprint that includes traces of primary and secondary trail. The main carbon footprint represents the amount of $\mathrm{CO} 2$ emissions that occur directly from use of fossil fuels, while the secondary carbon footprint accumulated indirect carbon source and as an example is electricity. Another definition of carbon footprint is estimated individual in contributing to global warming which is calculated based on the unit that is equivalent to the $\mathrm{CO} 2$ [5].

In this context, electricity consumption and carbon footprint are closely related as electricity is considered to be the source of secondary carbon footprint. UI GreenMetric collected both the electricity and carbon footprint data. In this work, we evaluate the electricity consumption and carbon footprint data in UI GreenMetric database. A regression analysis is proposed such that we can guess the electricity usage of certain universities which do not fill the data or fill the data with zero. By this means, the accuracy of the produced rank can be retained up to some degree.

Performing calculation of carbon footprint can increase the awareness of how much carbon emission one has produced during certain periods, which may lead to carbon emission reduction. According to a study by Lambrechts dan Liedekerke (2014) Of Leuven University College (KHLeuven), mobility from transportation contributes to 3.362 ton $(44.22 \%)$, nearly half from total carbon footprint. UK Higher Education Funding Council for England (HEFCE) encourage higher education institution to reduce carbon emission (HEFCE, 2010a). After conducting the measurement and calculation of its greenhouse gas emissions, which of course include $\mathrm{CO}_{2}$, Yale University pledged to reduce its greenhouse gas emissions 43\% below 2005's levels by 2020. Currently, Yale University has achieved a $12 \%$ reduction, despite a
$14 \%$ increase in campus size [6]. The ecological footprint from carbon footprint is very important, UI GreenMetric already use question to evaluate this. This paper will present method and analytical aspect of data related with ecological footprint.

\section{Methodology}

In this work we evaluate the university's annual electricity consumption and carbon footprint. For the electricity consumption evaluation, mainly we utilize the information of annual electricity consumption per-capita from the World Bank which has been specified for every country. Subsequently we match and compare it with the data from UI GreenMetric, i.e. the campus population, and available annual electricity consumption. Using university's annual electricity consumption (AEC) data from UI GreenMetric, we performed some regression analysis. Regression analysis is often used to predict future electricity consumption [1] [2]. In this work we show AEC along with the carbon footprint from universities to see its relation. We valuated some specific targeted countries as the sample to show how the prediction can be done for the blank data.

While the AEC value is taken from UI GreenMetric database, the predicted AEC is calculated as:

$$
A E C \text { est. }=\text { num. of population } \times A E C \text { per kapita (1) }
$$

where the number of population is taken from UI GreenMetric database. Subsequently, regression is performed to find the trendline of the AEC vs predicted AEC. To calculate prediction of AEC from universities we are using formula 1 .

\section{Result and discussion}

In the following, the result of AEC vs Predicted AEC is plotted. Each dot represents one university. The trendline is drawn based on linear regression against the scattered dots. Notice that in this 2D plots, the preferred situation is when all dots concentrate in one area or close to the trend-line. When it happens, it means the data is good as predicted, and also confirm the accuracy of the prediction.

\subsection{Electricity consumption}

Based on regression analysis we can create function to predict annual electricity consumption from certain country. Figures $1,2,3,4,5$, and 6 show the annual electricity consumption from universities in Indonesia, Taiwan, Colombia, Italy, Malaysia and Russia. 


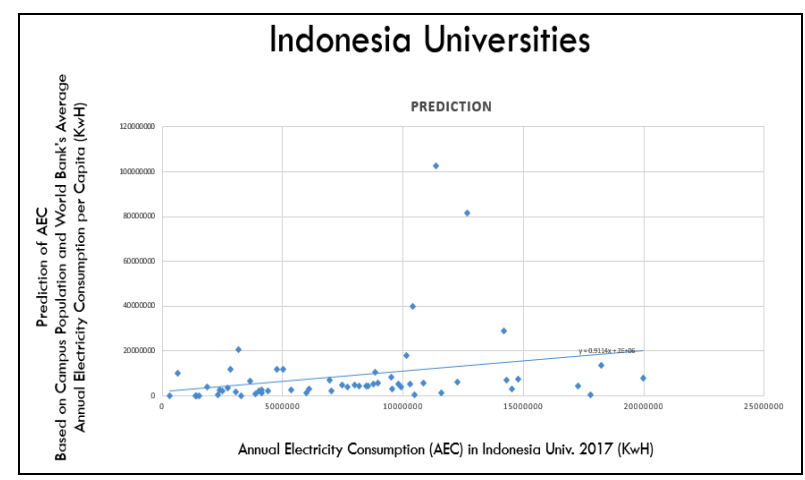

Fig. 1. Indonesia universities electricity consumption

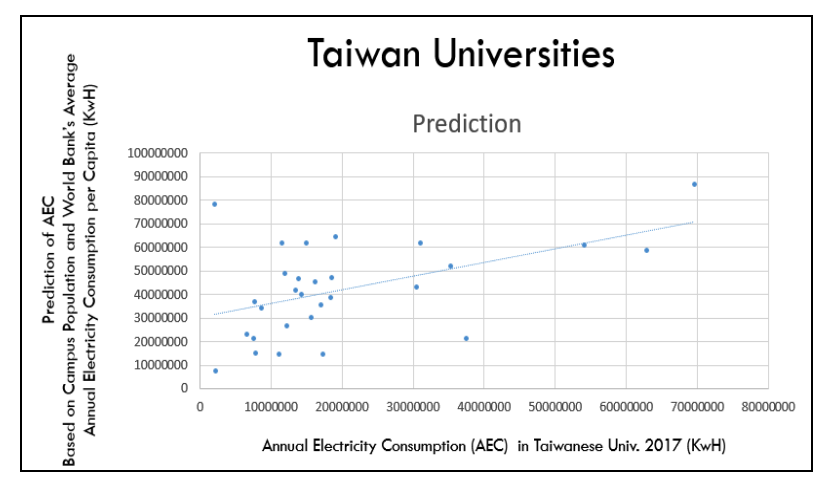

Fig. 2. Taiwan universities electricity consumption

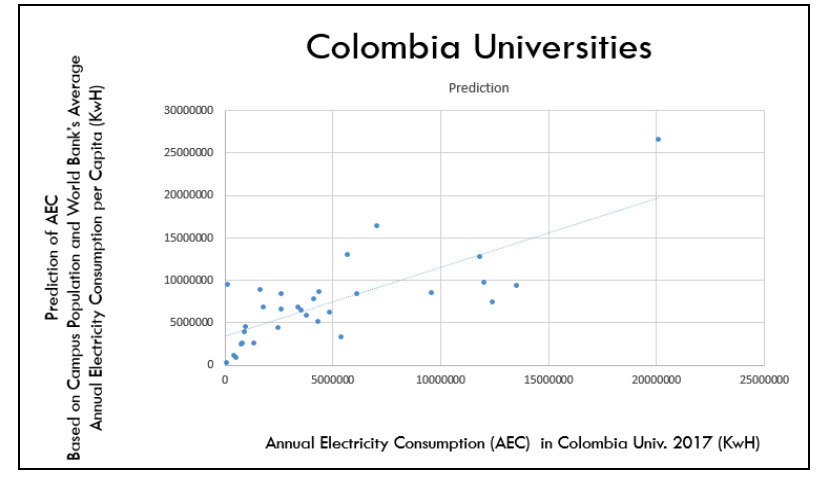

Fig. 3. Colombia universities electricity consumption

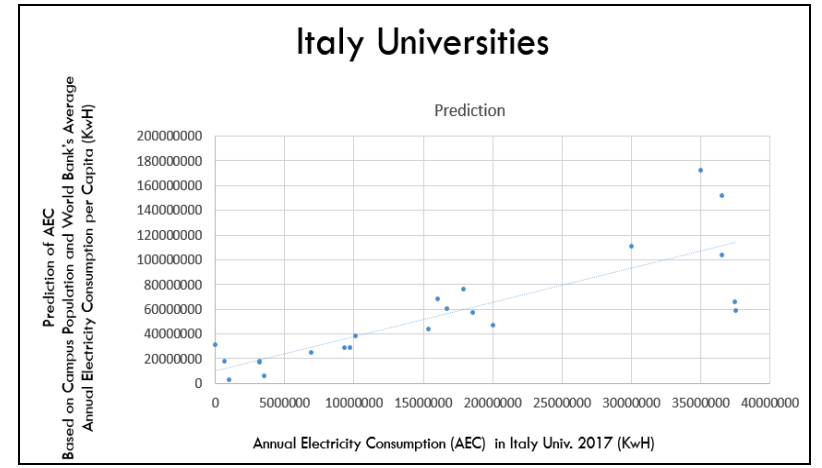

Fig. 4. Italy universities electricity consumption

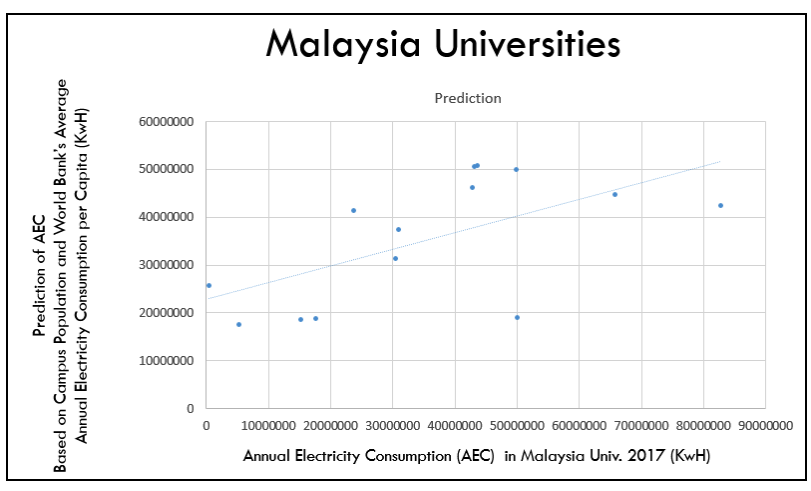

Fig. 5. Malaysia universities electricity consumption

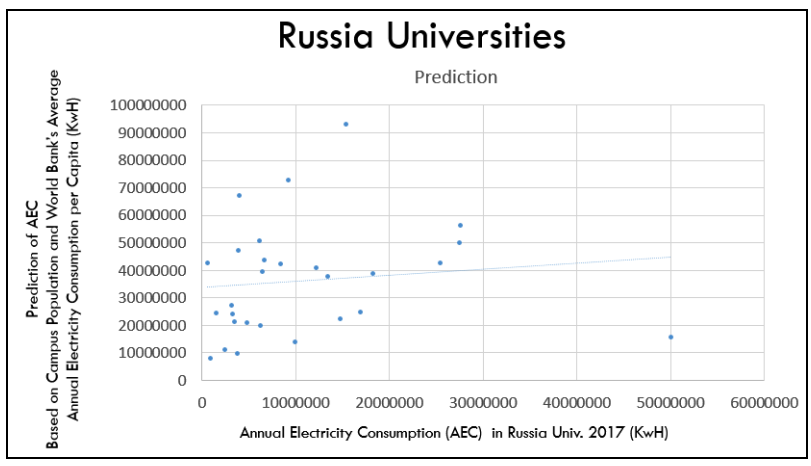

Fig. 6. Russia universities electricity consumption

Based on the Figures 1,2,3,4,5, and 6, we can estimate the universities annual electricity consumption. The function of trend-line gradient only work for specific country. As shown in the Figures, different country may have different trend-line obtained by regression method.

The results for Indonesia and Italy, which are shown in Figures 1 and 4, respectively, tend to concertize close with normal line. The results for Taiwan and Russia, which are shown in Figures 2 and 6, respectively, have more scattered pattern. The result for Columbia and Malaysia have almost similar gradient of the trend-line, as shown in Figures 3 and 4, respectively, which is larger than the gradient of the other 4 countries. The quantity of the outlier's data also different.

In these 2D plots, we can observe some outlier sample. Our original hypothesis is that these outliers are generated by wrong data inputs. However, we find that different university may need to power different electronic appliances in their core business. For example, science and engineering related universities may need more electricity than that of social studies. Hence, for UI GreenMetric, these results are useful to decide which universities needs further verification. It will be very ideal if UI GreenMetric can perform rigorous verification to all of the universities. However, this mechanism will reduce complexity and cost of self-assessment. On the following steps, this is also important to maintain the current university network and encourage more universities to join UI GreenMetric and create more green campuses in the world. 


\subsection{Carbon footprint}

As explained in the background part. Carbon footprint has correlation with AEC. This is because electricity is one of the source of secondary carbon footprint. In the following, we plotted the annual carbon footprint versus the AEC from universities in Indonesia, Taiwan, Colombia, Italy, Malaysia and Russia.

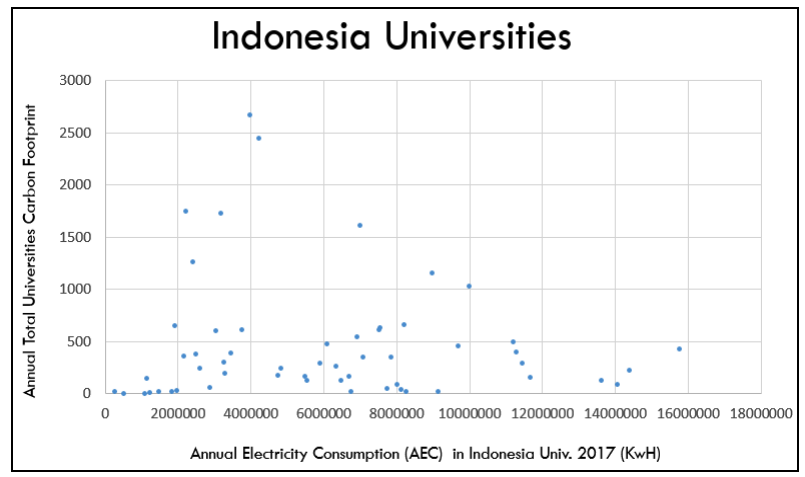

Fig. 7. Indonesia universities AEC vs carbon footprint

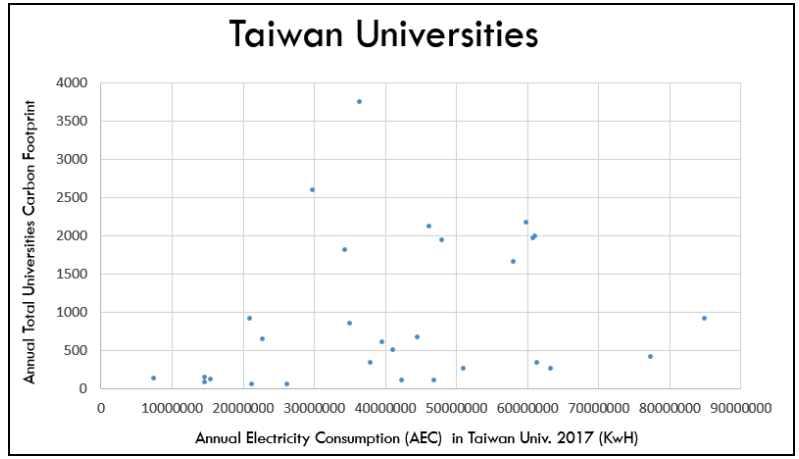

Fig. 8. Taiwan universities AEC vs carbon footprint

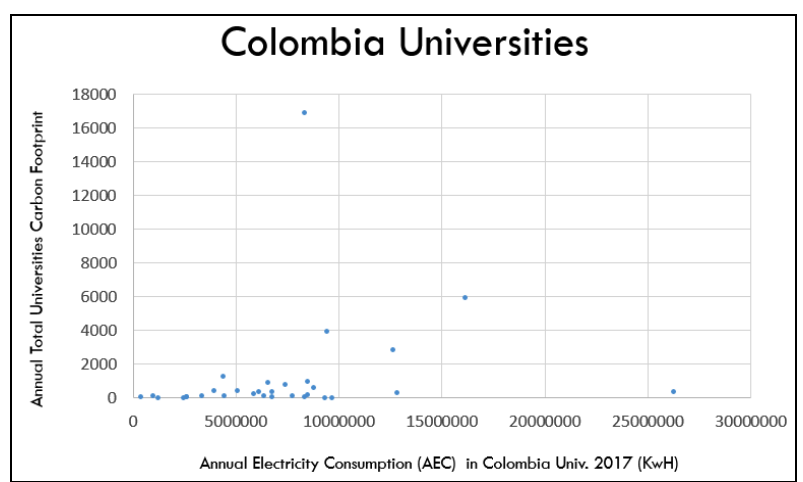

Fig. 9. Colombia universities AEC vs carbon footprint

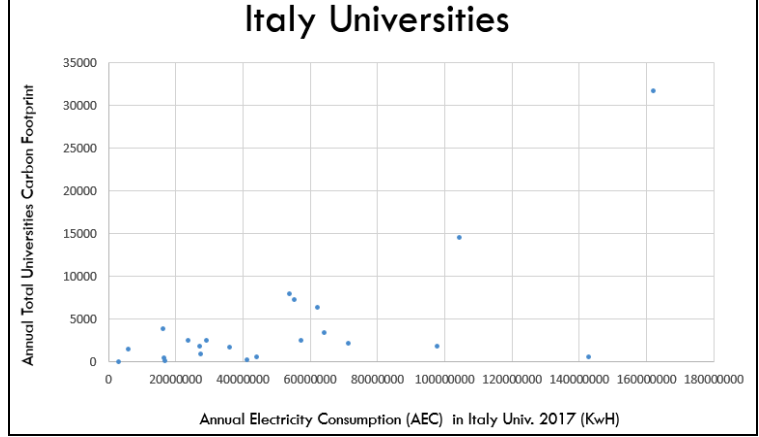

Fig. 10. Italy universities AEC vs carbon footprint

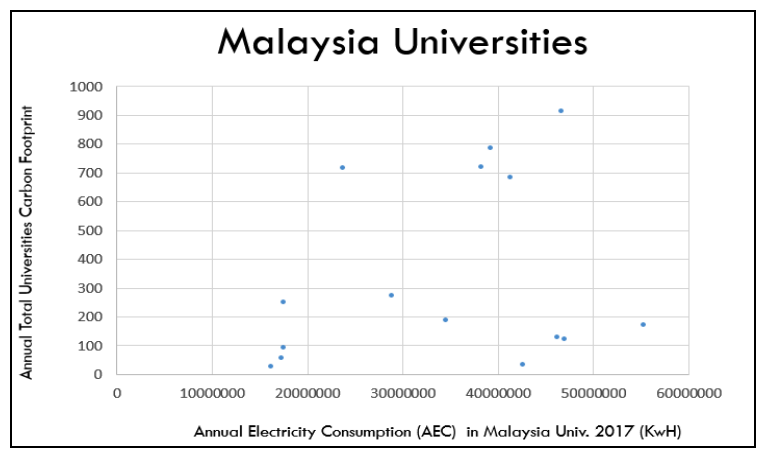

Fig. 11. Malaysia universities $A E C$ vs carbon footprint

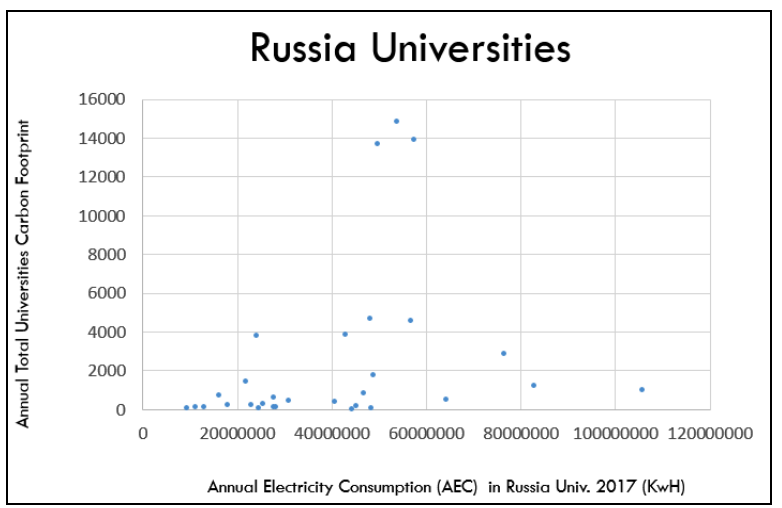

Fig. 12. Russia universities AEC vs carbon footprint

Based on these 2D plots on Figures 7,8,9,10,12 and 12, the annual carbon footprint and the AEC have scattered pattern in each country. There is no significant insight can be taken into consideration based on the regression analysis. Our hypothesis of this phenomenon is that the calculation of carbon footprint, as shown in UI GreenMetric guideline, cannot be generalized due to different business process in each university in the same country. 


\section{Conclusion and evaluation}

According to the regression test, every country tends to have different pattern. Because of this pattern, method of regression cannot be applied homogenously to all participating universities in UI GreenMetric. Regression method may be relevant and applicable for certain country which has normal pattern around the trend line. Some of countries may have more scattered pattern to make predictive model for AEC less accurate. Overall prediction based on the current pattern is still appropriate for certain countries. For future work more advance method may be applied to predict more accurate AEC from every Universities in different Countries. On the other hand, comparison between AEC and carbon footprint does not have significant result based on regression analysis. This is because the result tends to be scattered. For the future work, we will consider different factors that differentiate university's electricity consumption such as the existence of large laboratory and other highly electricity consumptive equipment. Other method to evaluate the electricity consumption and carbon footprint in universities will be conducted.

\section{References}

1. Braun, M. R., H. Altan, and S. B. M. Beck, Using regression analysis to predict the future energy consumption of a supermarket in the UK, Applied Energy 130: 305-313, M. Ben Rabha, M.F.
Boujmil, M. Saadoun, B. Bessaïs, Eur. Phys. J. Appl. Phys (2014)

2. Fumo, Nelson, and MA Rafe Biswas. Regression analysis for prediction of residential energy consumption. Renewable and Sustainable Energy Reviews 47: 332-343 (2015)

3. Chambers, N; C. Simmons, M. Wackernagel, Sharing Nature's Interest. Earthscan Publications Ltd. London, UK (2000)

4. Wiedmann, Thomas, et al. Multiregional inputoutput modelling opens new opportunities for the estimation of ecological footprints embedded in international trade. International Ecological Footprint Conference, Cardiff (2007)

5. Lynas M. 2007, Carbon Counter. Glasgow: HarperCollins Publishers.dalam jurnal Kenny, T and Gray, N. F, 2009, Comparative performance of six carbon footprint models for use in Ireland, Environmental Impact Assessment Review 29 1-6 (2009)

6. Yale University, Greenhouse Gas Emissions Reduction Progress, US (2015)

7. Wackernagel, Mathis, and William Rees, Our ecological footprint: reducing human impact on the earth, 9, New Society Publishers (1998)

8. Jeongho Woo, Kyoung-Sik Choi, Analysis of Potential Reductions of Greenhouse Gas Emissions on the College Campus through the Energy Saving Action Programs, Republic of Korea (2013) 